\title{
Quantitative measurement of faecal blood loss: Comparison of radioisotopic and chemical analyses
}

\author{
M B G Leahy, M J Pippard, M B Salzmann, M G Rinsler, R Hesp, T Smith
}

\begin{abstract}
Blood loss in faeces was assessed by three different methods in five patients with recurrent iron deficiency. In short term (12 day) studies chemical analysis of complete stool collections for haemderived porphyrins (HemoQuant) gave results closely correlated with those obtained by measuring stool loss of ${ }^{51} \mathrm{Cr}$ labelled red blood cells. Whole body counting for ${ }^{59} \mathrm{Fe}$ was relatively insensitive to small blood losses but allowed losses to be followed up over longer periods. Chemical analysis of faecal porphyrins thus provides a satisfactory alternative to radioisotopic techniques in short term quantitation of faecal blood loss, while longer term whole body counting of ${ }^{59} \mathrm{Fe}$ may still be appropriate in a few patients for the detection and quantification of intermittent blood losses.
\end{abstract}

Chronic blood loss into the gastrointestinal tract is a common cause of iron deficiency and may be the first indication of serious gut disease. Chemical tests based on the pseudoperoxidase activity of haemoglobin have been used to screen for faecal occult blood, but have the disadvantage that they are not specific for blood ${ }^{1}$ and generate a high rate of false positive results. ${ }^{2}$ They also depend on other variables including interfering factors and degradation of the haemoglobin, giving rise to false negative results. ${ }^{3}$ They give no indication of the amount of blood loss; radioisotopic labelling of red cells has been used for this. Such tests commonly involve measurement, in complete stool specimens, of the loss of red cells reinjected after extrinsic labelling with ${ }^{51} \mathrm{Cr},{ }^{4}$ and it is rarely practicable to continue studies beyond a few days. Less frequently the loss of red cells intrinsically labelled by intravenous injection of ${ }^{59} \mathrm{Fe}$ has been followed up, either by direct counting of the stools, or by repeated counting of total body radioactivity to assess retention of ${ }^{59} \mathrm{Fe}$ within the body. Such studies usually assume that after intravenous injection ${ }^{59} \mathrm{Fe}$ is totally incorporated into red cells by seven to 10 days, and that any loss in total body counts after correction for decay is entirely due to blood loss. ${ }^{5}$ The whole body counting technique has the advantage that it can be carried out over prolonged periods on outpatients, but requires equipment which is not generally available. Previous comparison of ${ }^{51} \mathrm{Cr}$ and ${ }^{59} \mathrm{Fe}$ techniques has shown a reasonable correlation in patients with inflammatory bowel disease. ${ }^{6}$ More recently, a chemical analysis has been described in which faecal haem is converted to porphyrin before quantitative determination." This "HemoQuant" assay is a more sensitive and precise measure of gastrointestinal bleeding than at least one method of qualitative faecal occult blood testing, ${ }^{8}$ but the possibility of its use for measuring complete daily stool blood losses compared with quantitation of losses using radioisotopic red cell labels has not previously been investigated.

In this study we compared ${ }^{51} \mathrm{Cr}$ labelled red cell losses in the faeces with those measured by porphyrin assay, and compared these short term studies (12 days) with longer term measures (up to three months) of blood loss using ${ }^{59} \mathrm{Fe}$ whole body counting. The aim was to determine the potential strengths and weaknesses of each technique in the investigation of patients with iron deficiency that is recurrent or unresponsive to iron treatment and in whom the amount and source of blood loss remains doubtful. A further stimulus to the study was the possibility that chemical determination of faecal porphyrins could avoid exposure to ionising radiation, particularly in normal volunteers undertaking physiological or pharmacological studies.

\section{Methods}

Five patients with recurrent iron deficiency in whom screening tests for faecal occult blood had been intermittently positive had undergone extensive gastrointestinal, radiological, and endoscopic investigations (table 1). In all cases there was continuing doubt over the rate and exact source of blood loss. Patients who were taking regular oral iron treatment were asked to stop this 48 hours before attending for ${ }^{59} \mathrm{Fe}$ injection (see below) to ensure that there was plentiful free plasma iron binding capacity to take up the injected radioiron. Oral iron treatment was resumed the following day.

${ }^{59} \mathrm{FE}$ AND ${ }^{51} \mathrm{CR}$ RADIOISOTOPE STUDIES ${ }^{59} \mathrm{Fe}$-Citrate (Amersham, UK), $37 \mathrm{kBq}(1 \mu \mathrm{Ci})$ in $1 \mathrm{ml}$ saline at $\mathrm{pH} 3$, was injected intravenously over two minutes immediately after a background total body count using a multicrystal whole body counter. ${ }^{9}$ A second total body count immediately after ${ }^{59} \mathrm{Fe}$ injection was used to give a value for $100 \%$ retention of the radioiron. 
Table 1 Patient characteristics at start of study

\begin{tabular}{|c|c|c|c|c|c|c|c|c|}
\hline \multirow[b]{2}{*}{$\begin{array}{l}\text { Case } \\
\text { No }\end{array}$} & \multirow[b]{2}{*}{ Sex } & \multirow[b]{2}{*}{$\begin{array}{l}\text { Age } \\
\text { (years) }\end{array}$} & \multirow[b]{2}{*}{$\begin{array}{l}H b \\
(g / l)\end{array}$} & \multirow[b]{2}{*}{$\begin{array}{l}M C V \\
(f)\end{array}$} & \multicolumn{3}{|l|}{ Serum } & \multirow[b]{2}{*}{$\begin{array}{l}\text { Gastrointestinal } \\
\text { radiology/endoscopy }\end{array}$} \\
\hline & & & & & $\begin{array}{l}\text { Iron } \\
(\mu \mathrm{mol} / l)\end{array}$ & $\begin{array}{l}\text { TIBC } \\
(\mu \mathrm{mol} / \mathrm{l})\end{array}$ & $\begin{array}{l}\text { Ferritin } \\
(\mu g \mid l)\end{array}$ & \\
\hline $\begin{array}{l}1 \\
2 \\
3 \\
4 \\
5 \\
\text { Refer }\end{array}$ & $\begin{array}{l}\mathbf{F} \\
\mathbf{M} \\
\mathbf{M} \\
\mathbf{F} \\
\mathbf{M} \\
\text { nges }\end{array}$ & $\begin{array}{l}70 \\
54 \\
66 \\
49 \\
21\end{array}$ & $\begin{array}{r}131 \\
141 \\
146 \\
130 \\
76\end{array}$ & $\begin{array}{l}96 \\
82 \\
87 \\
87 \\
59 \\
80-94\end{array}$ & $\begin{array}{c}13 \\
18 \\
6 \\
13 \\
1 \\
11-28\end{array}$ & $\begin{array}{r}72 \\
84 \\
111 \\
69 \\
111 \\
45-70\end{array}$ & $\begin{array}{l}37 \\
16 \\
14 \\
35 \\
8 \\
16-250\end{array}$ & $\begin{array}{l}\text { Hiatus hernia } \\
\text { Small bowel stricture } \\
\text { Oesophagitis/duodenitis } \\
\text { Normal } \\
\text { Normal }\end{array}$ \\
\hline
\end{tabular}

Ten days later the patients were admitted to a metabolic ward. A further ${ }^{59} \mathrm{Fe}$ total body count was made immediately before and again after injection of autologous red cells labelled with ${ }^{51} \mathrm{Cr}(1.85 \mathrm{MBq} ; 50 \mu \mathrm{Ci})$ by the citrate wash method ${ }^{10}:$ no disturbance of ${ }^{59} \mathrm{Fe}$ counts was seen as a result of ${ }^{51} \mathrm{Cr}$ injection. The red cell mass was determined by blood sampling at 10 and 60 minutes following the ${ }^{51} \mathrm{Cr}$ red cell injection and counting $3 \mathrm{ml}$ of blood (haemolysed with saponin) against a standard containing a known weight of the injected ${ }^{51} \mathrm{Cr}$ red cells. Appropriate corrections were made for cross counting of ${ }^{59} \mathrm{Fe}$ into the ${ }^{51} \mathrm{Cr}$ channel on a well-type gamma counter (Wallac $\mathbf{8 0 0 0 0}$ with a 3 inch crystal). Over the next 12 days all stools were collected and individually counted for ${ }^{51} \mathrm{Cr}$ in a large volume counter ${ }^{11}$ using counts in diluted blood samples, taken on alternate days, as a reference to calculate the amount of blood lost in each stool. After counting, the individual stools were frozen at $-20^{\circ} \mathrm{C}$ for subsequent porphyrin analysis. Whole body ${ }^{59} \mathrm{Fe}$ counts were made at roughly seven day intervals for at least 60 days.

Red cell utilisation of ${ }^{59} \mathrm{Fe}$ was calculated from the ${ }^{59} \mathrm{Fe}$ counts in unit volume of blood at 10 days following ${ }^{59} \mathrm{Fe}$ injection and the measured ${ }^{51} \mathrm{Cr}$ red cell mass. Changes in whole body radioactivity were expressed as a percentage of the total ${ }^{59} \mathrm{Fe}$ dose injected and compared with the percentage of the total dose remaining in unit volume of whole blood counted against a standard at each visit. The change in percentage whole body retention of ${ }^{59} \mathrm{Fe}$ divided by the mean value for ${ }^{59} \mathrm{Fe}$ remaining in $1 \mathrm{ml}$ of whole blood was used to calculate the blood loss.

Blood loss ( $\mathrm{ml}$ ) between days $\mathrm{t}$ and $\mathrm{t} 1=$

$\left(\% \text { retention }{ }^{59} \mathrm{Fe}\right)_{\mathrm{t}}-\left(\% \text { retention }{ }^{59} \mathrm{Fe}\right)_{\mathrm{t} 1}$

( $\%$ injected counts per ml blood $_{t}+\%$ injected counts per $\mathrm{ml}$ of blood $\left._{\mathrm{t} 1}\right) / 2$

Table 2 Comparison of faecal blood losses determined by short term (12 day) measures of faecal ${ }^{59} \mathrm{Cr}$-labelled red cells or more prolonged measures ( 60 days) of ${ }^{59} \mathrm{Fe}$ by total body counting

\begin{tabular}{|c|c|c|c|}
\hline \multirow[b]{2}{*}{ Case No } & \multicolumn{3}{|c|}{ Blood loss (ml/day) } \\
\hline & ${ }^{s t} \mathrm{Cr}$ & ${ }^{59} \mathrm{Fe}(A)^{\star}$ & ${ }^{59} \mathrm{Fe}(\mathrm{B})$ * \\
\hline $\begin{array}{l}1 \\
2 \\
3 \\
4 \\
5\end{array}$ & $\begin{array}{r}2 \cdot 7 \\
23.0 \\
8.5 \\
0.6 \\
1 \cdot 1\end{array}$ & $\begin{array}{r}36 \cdot 7 \\
22 \cdot 0 \\
12.5 \\
3.8 \\
1.6\end{array}$ & $\begin{array}{r}42 \cdot 3 \\
27 \cdot 3 \\
20 \cdot 2 \\
3 \cdot 7 \\
2 \cdot 3\end{array}$ \\
\hline
\end{tabular}

*Includes whole blood losses by venous sampling $(80 \mathrm{ml}$ in first 12 days and a further $30 \mathrm{ml}$ thereafter).

A: direct measures of ${ }^{59} \mathrm{Fe}$ remaining in the blood and the total body.

B: calculation from the fractional change in total body counts and estimated blood volume.

The pronounced discrepancy between ${ }^{51} \mathrm{Cr}$ and ${ }^{59} \mathrm{Fe}$ measurements in case 1 may have been the result of intermittent bleeding undetected by short term studies.
This value for blood loss was compared with blood loss calculated from the blood volume estimated from the patient's surface area ${ }^{12}$ and the fractional change in ${ }^{59} \mathrm{Fe}$ total body counts between each visit, assuming that $100 \%$ of the ${ }^{59} \mathrm{Fe}$ had been used for red cell haemoglobin synthesis.

In a different study of whole body ${ }^{59} \mathrm{Fe}$ loss repeated whole body measurements requ iring repositioning of the patient on the couch gave a mean paired difference of 0.66 (SD 0.48 ) \% $(n=18)$. If reasonable errors of $1 \%$ are ascribed to counting geometry and blood sample pipetting, in addition to errors based on counting statistics alone, an overall variation of up to $70-80 \mathrm{ml}$ may be expected on an estimated $500 \mathrm{ml}$ blood loss.

\section{FLUORESCENCE MEASUREMENT OF FAECAL} PORPHYRINS

After thawing, faecal samples were weighed, homogenised using a Colworth Stomacher Lab-Blender 400, and assayed, in duplicate, for haemoglobin content by the "HemoQuant" method. ${ }^{7}$ This depends on the conversion of haemoglobin to porphyrins which can be quantitated by a measurement of fluorescence. A saturated hot oxalic acid reagent solubilises porphyrins already present in the faeces as a result of haem degradation during transit through the gut, and also reduces haem to various dicarboxylic porphyrins. The final figure is therefore a measure of total blood loss into the gastrointestinal tract and not just that surviving gut transit in the form of haem. A commercial cyanmethaemoglobin preparation (BDH clinical reagents) was used as a standard and taken through conversion, extraction, and purification stages alongside the faecal samples, together with a blank and an in-house cyanmethaemoglobin control prepared in Aculute (Ortho Diagnostics). Fluorescence of the samples was measured within 24 hours of the extractions on a Perkin Elmer LS-3 fluorimeter, using an excitatory wave length of $408 \mathrm{~nm}$ and an emission wavelength of $654 \mathrm{~nm}$. Results in $\mathrm{mg}$ haemoglobin/g faeces were converted to blood loss ( $\mathrm{ml} /$ stool sample) using the peripheral blood haemoglobin concentration measured on alternate days and the known faecal weights. This method gives $99 \%$ recovery for blood added directly to stool samples $^{3}$ and a mean of $88 \%$ recovery from ingested human blood. ${ }^{13}$ In this study the within-batch coefficient of variation for repeated assays was $10 \%$ at a mean value of $2.46 \mathrm{mg}$ haemoglobin $/ \mathrm{g}$ faeces $(\mathrm{n}=8)$ and $7 \%$ at a mean value of $14.22 \mathrm{mg}$ haemoglobin $/ \mathrm{g}$ faeces $(n=10)$. 
Figure 1 Daily variation in faecal blood loss: comparison of measurements by ${ }^{51} \mathrm{Cr}$ labelling of red cells (-) and porphyrin assay (-- -) in case 2.

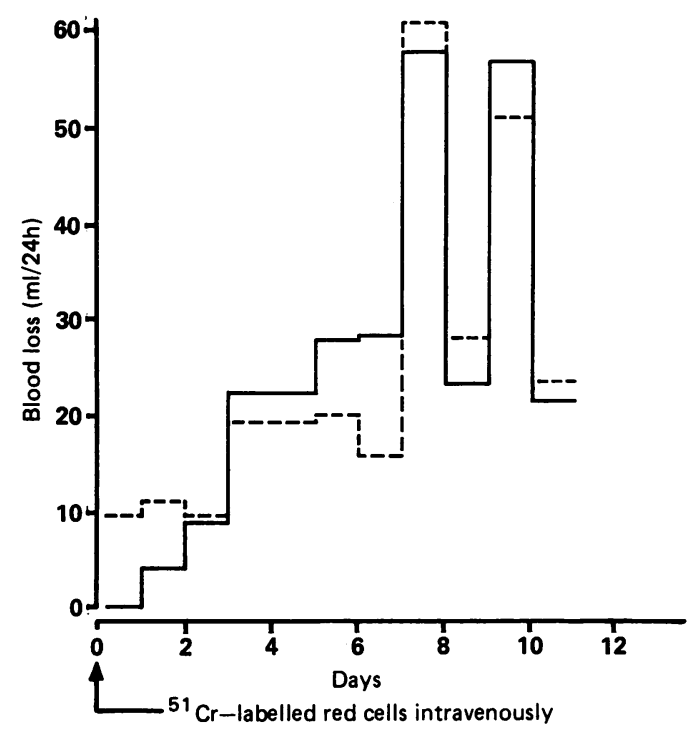

\section{Results}

COMPARISON OF ${ }^{51}$ CR AND PORPHYRIN ASSAYS

Daily variations in blood loss during the 12 days of stool collections in case 2 were similar with both methods (fig 1). An excess of blood loss measured by porphyrin assay during the first two days after injection of ${ }^{51} \mathrm{Cr}$-labelled red cells may be attributed to the time taken for blood loss that has been labelled by ${ }^{51} \mathrm{Cr}$ to appear in the faeces-that is, the bowel transit time. Stools selected from all five patients at least three days after injection of ${ }^{51} \mathrm{Cr}$-labelled red cells showed an excellent correlation between the two measures of blood loss, though with a tendency for the porphyrin measurement to underestimate by about $10 \%$ with respect to the ${ }^{51} \mathrm{Cr}$ measurement (fig 2).

\section{${ }^{59}$ FE BLOOD LOSS STUDIES}

Whole body ${ }^{59} \mathrm{Fe}$ counts 10 days after intravenous injection of ${ }^{59} \mathrm{Fe}$ were $99.6 \%$ of those obtained immediately after the injection (range $98 \cdot 8$ to $100 \cdot 2 \%$ ). Blood utilisation of the ${ }^{59} \mathrm{Fe}$ injected 10 days earlier was $87 \%$ (range 81 $91 \%$ ) at the start of the blood loss studies. Cumulative measures of blood loss calculated from changes in ${ }^{59} \mathrm{Fe}$ counts in the total body and in blood samples showed minimal losses in cases 4 and 5, a steady rate of loss in cases 2 and 3 , and a pronounced increase in the rate of loss half way through the study in case 1 (fig 3 ).

Figure 2 Comparison of faecal blood loss in patients measured by ${ }^{\text {sI }}$ Cr counting and porphyrin assay in individual stool samples selected from five patients selected from five paic $y=0.91 x-0.92)$.

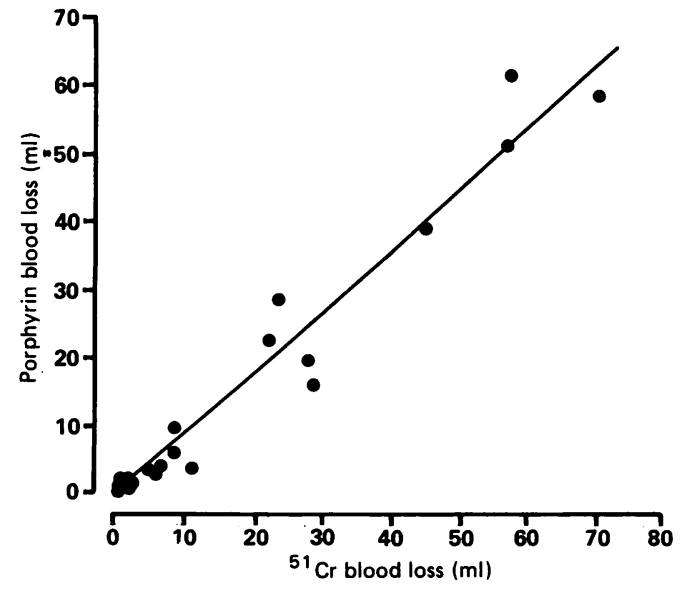

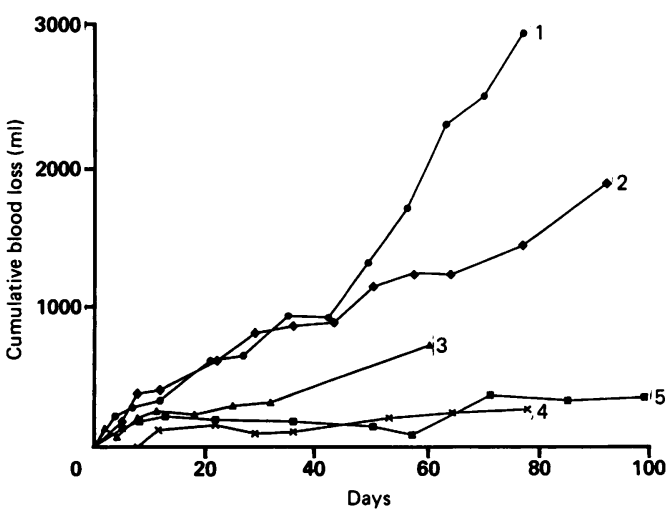

Figure 3 Cumulative blood losses measured by serial total body and blood ${ }^{59} \mathrm{Fe}$ counts in five patients.

In all the patients except case 1 , there was reasonable agreement between daily blood loss calculated from ${ }^{51} \mathrm{Cr}$ counts during the 12 days of stool collections and loss of whole body ${ }^{59} \mathrm{Fe}$ over 60 days (table 2). There were considerable variations, however, in blood losses measured by whole body counting of ${ }^{59} \mathrm{Fe}$ in those patients who showed a relatively small cumulative blood loss (cases 4 and 5 ). ${ }^{59} \mathrm{Fe}$ estimates during the first 12 days of the study also generally overestimated blood losses compared with ${ }^{51} \mathrm{Cr}$ measurements. This may be partially explained by the venous blood sampling necessary for these studies, but whole body counting errors at low levels of blood loss are also likely to play their part.

Blood losses calculated from the ${ }^{59} \mathrm{Fe}$ counts using the fractional change in total body retention and blood volumes estimated from the patients' height and weight were generally comparable with those derived from direct measurements of the remaining blood ${ }^{59} \mathrm{Fe}$ (table 2).

\section{Discussion}

This study has shown that a quantitative measurement of porphyrin derivatives of haemoglobin within stool samples gives results comparable with the use of ${ }^{51} \mathrm{Cr}$ in the assessment of short term stool blood losses where it could thus replace the use of radioisotopes: this is likely to be of particular importance where normal volunteers are being used in drug studies. The tendency for the porphyrin measurement to underestimate slightly blood loss with respect to the ${ }^{51} \mathrm{Cr}$ measurement (fig 2) may reflect the availability of haem for gastrointestinal absorption. ${ }^{14}$ Such absorption may account for the previous observation that only $88 \%$ of haem from ingested human blood is recovered by porphyrin assay, ${ }^{13}$ could also affect measurements using ${ }^{59} \mathrm{Fe}$, and may be expected to be relatively more important at low rates of blood loss. Like the use of ${ }^{51} \mathrm{Cr}$ label, quantitative determination of blood loss by measurement of porphyrin derivatives has the disadvantage of requiring collection of all stools with an additional requirement for homogenisation before assay.

Ingestion of dietary haem proteins, such as red meat, may increase stool porphyrins in normal volunteers, ${ }^{15}$ and although no special 
dietary restrictions were made in the present study, where blood losses are close to the upper limit of normal ( $2 \mathrm{ml} /$ day $)^{16}$ a diet free of red meat may enhance accuracy. ${ }^{17}$

Any method based on short term stool collections has an inherent risk of missing intermittent blood loss, as illustrated by case 1. By contrast, although ${ }^{59} \mathrm{Fe}$ total body counting gives inaccurate measures of small blood losses because counting and geometry errors fall within the range to be assessed, the technique allows losses to be followed over much longer periods as an outpatient. This approach may thus remain helpful in quantifying intermittent blood loss in a few patients with unexplained iron deficiency, particularly where short term stool porphyrin measurements have not shown any clinically important blood loss.

We are grateful to Dr Jonathan Levi, consultant physician, Northwick Park Hospital, for allowing us to study the patients Physics Department, where dispensing of radioisotopes and counting of ${ }^{31} \mathrm{Cr}$ stool samples was performed.

1 Irons GV, Kirsner JB. Routine chemical tests of the stools for occult blood: an evaluation. $A m J M e d S c i$ 1965;249:247-60.

2 Robertson JD, Maughan RJ, Davidson RJL. Correlation between qualitative and quantitative faecal occult blood tests. Clin Chim Acta 1987;170:339-44.

3 Ahlquist DA, McGill DB, Schwartz S, Taylor WF, Ellefson M, Owen RA. HemoQuant, a new quantitative assay for fecal hemoglobin. Comparison with Hemoccult. Ann Intern Med 1984;101:297-302.

4 Bannerman RM. Measurement of gastrointestinal bleeding using radioactive chromium. Br Med J 1957;2:1032-4.

5 Holt JM, Mayet FGH, Warner GT, Callender ST. Measurement of blood loss by means of a whole-body counter. Br Med J 1967;4:86-8.

6 Stack BHR, Smith T, Hywel Jones J, Fletcher J. Measurement of blood and iron loss in colitis with a whole-body counter. Gut 1969;10:769-73.

7 Schwartz J, Dahl J, Ellefson M, Ahlquist D. HemoQuant test: a specific and quantitative determination of heme (hemoglobin) in feces and other materials. Clin Chem 1983;29:2061-7.

8 Ahlquist DA, Douglas B, McGill MD, Schwartz S, Taylor WF, Owen RA. Fecal blood levels in health and disease. N Engl J Med 1985;212:1422-8.

9 Smith T, Hesp R, Mackenzie J. Total body potassium calibrations for normal and obese subjects in two types of whole body counter. Phys Med Biol 1979;24:171-5.

10 International Committee for Standardization in Haematology. Recommended methods for radioisotope Haematology. Recommended methods for radioisotope
red-cell survival studies. Br J Haematol 1971;21:241-50.

11 Cronquist AG, Mackenzie J, Smith T. A high resolution bulk-sample counter with variable geometry. International Journal of Applied Radiation and Isotopes 1975;26:89-91.

12 Retzlaff JA, Tauze WN, Kielly JM, Stroebal CF. Erythrocyte volume, plasma volume and lean body mass in adult men and women. Blood 1969;33:649-67.

13 Schwartz S, Ellefson M. Quantitative fecal recovery of ingested hemoglobin-heme in blood: comparisons by HemoQuant assay with ingested meat and fish. Gastroenterology 1985;89:19-27.

14 Raffin SB, Woo CH, Roost KT, Price DC, Schmid R. Intestinal absorption of hemoglobin iron-heme cleavage by mucosal heme oxygenase. J Clin Invest 1974;54: by mucosal

15 Rose IS, Young GP, St John DJ, Deacon MC, Blake D, Henderson RW. Effect of ingestion of hemoproteins on fecal extraction of hemes and porphyrins. Clin Chem 1989;35:2290-6.

16 Simon JB. Occult blood screening for colorectal carcinoma: a critical review. Gastroenterology 1985;88:820-37.

17 Feinberg EJ, Steinberg WM, Banks BL, Henry JP. How long to abstain from eating red meat before fecal occult blood tests. Ann Intern Med 1990;113:403-4. 